\title{
Assessment of Incidentally Detected Simple Renal Cyst in Pediatric Patient Based on the Modified Bosniak Classification
}

\section{-Incidentally Detected Simple Renal Cyst in Pediatric}

\author{
Amna Kashgari1,2*, Eman Ajlan1, Abdullah Al Hammad1, Syed Jamil1,3 \\ ${ }^{1}$ King Saud Bin Abdulaziz University for Health Sciences, Riyadh, Saudi Arabia \\ ${ }^{2}$ Medical Imaging Department, King Abdullah Specialized Children Hospital/King Saud Bin Abdulaziz University for Health \\ Science, Riyadh, Saudi Arabia \\ ${ }^{3}$ Pediatric Department, King Abdullah Specialized Children Hospital/King Saud Bin Abdulaziz University for Health Science, \\ Riyadh, Saudi Arabia \\ Email: ^drakashgari@ngha.med.sa
}

How to cite this paper: Kashgari, A., Ajlan, E., Al Hammad, A. and Jamil, S. (2020) Assessment of Incidentally Detected Simple Renal Cyst in Pediatric Patient Based on the Modified Bosniak Classification. Open Journal of Pediatrics, 10, 356-362. https://doi.org/10.4236/ojped.2020.102036

Received: May 20, 2020

Accepted: June 26, 2020

Published: June 29, 2020

Copyright $\odot 2020$ by author(s) and Scientific Research Publishing Inc. This work is licensed under the Creative Commons Attribution International License (CC BY 4.0).

http://creativecommons.org/licenses/by/4.0/

\begin{abstract}
Renal cysts in pediatric patients are uncommon lesion. A modified Bosniak classification system for renal cysts based on US has been developed to evaluate pediatric renal cysts to identify the simple cyst or cystic tumour. Nevertheless, it is not widely used. In this retrospective study, all incidentally detected renal cysts by ultrasound performed in children and the reproducibility of modified Bosniak classification to guide the radiological and clinical follow up.
\end{abstract}

\section{Keywords}

Renal Cyst, Ultrasound, Pediatric, Modified Bosniak Classification

\section{Introduction}

Pediatric renal cysts are uncommon [1]. In a large retrospective review of 16,102 abdominal sonographic studies performed on children with normal renal function and no family history of renal cystic disease, a prevalence of simple renal cysts noted to be $0.22 \%$ [2].

Most renal cysts are secondary to congenital or acquired conditions. However, incidentally detected renal cysts in ultrasound cause frequent clinical and radiological dilemmas. Many children continue to be monitored for changes in the appearance or number of the cysts [3].

The Bosniak classification was originally developed in adults to classify renal 
cysts. However, few studies in children suggest that this US based modified Bosniak classification is reliable to classify renal cysts in pediatric population [1] [4].

Limited evidence suggests that the risk of transformation of simple renal cysts to a renal malignancy in childhood is low [5]. Nevertheless, cystic renal tumors are so rare [6] [7]. Modified Bosniak classification gives criteria to diagnose a simple or complex renal cyst which aid the management and follow-up for the pediatric patient.

\section{Purpose}

The aim of this study is to evaluate the incidentally detected renal cysts in children based on the modified Bosniak classification and to examine their natural course.

\section{Methods}

This retrospective study was conducted at a King Abdullah Specialized Children Hospital (KASCH) which is affiliated with King Saud Bin Abdulaziz University of Health Sciences (KSAU-HS), Riyadh. The study includes all children below 14 years of age who were diagnosed with renal cyst by ultrasound during Jan 2014 to May 2018.

The exclusion criteria were the patients with genetic renal cystic disease, von Hippel-Lindau disease, tuberous sclerosis, multicystic kidney disease MCDK. The Patient files were assessed for age, gender, clinical presentation, urine analysis and renal function test. All available follow up US reviewed to study the natural course of the renal cysts.

Two radiologists, who were independent and blinded to clinical information, graded the cysts using the modified Bosniak classification system (Table 1).

\section{Results}

A 16 (9 female) cases were identified during the study period to have incidental renal cyst. Their age ranged from 2 days to 10 years (Table 2).

The clinical presentation of patients was varied, $5(31.25 \%)$ patients presented

Table 1. The modified Bosniak classification for renal cyst, based on ultrasound findings [4].

\begin{tabular}{ccc}
\hline Grade & Criteria & US echogenicity \\
\hline I & $\begin{array}{c}\text { Hairline thin wall, no nodule, no dopplar flow, } \\
\text { no calcification, no septations }\end{array}$ & Anechoic \\
II & $\begin{array}{c}\text { Hairline thin wall, no nodule, no dopplar flow, } \\
\text { no clacification, few thin septations }<1 \mathrm{~mm} .\end{array}$ & $\begin{array}{c}\text { Echogenic } \\
\text { (Debris or hemorrhage ) }\end{array}$ \\
III & $\begin{array}{c}\text { Thick wall }>1 \mathrm{~mm} \text {, multiple septations }>1 \mathrm{~mm}, \\
\text { no nodule, calcification and Doppler flow present. }\end{array}$ & Varies \\
IV & Soft tissue nodule & Soft tissue
\end{tabular}


Table 2. Patients demography, clinical presentation and US findings.

\begin{tabular}{|c|c|c|c|c|c|c|}
\hline Case & Age & sex & Clinical presentation & $1^{\text {st }}$ US result & Follow up US & Bosniak Classification \\
\hline 1 & $2 \mathrm{D}$ & $\mathrm{F}$ & Antenatal hydronephrosis & Simple renal cyst & Disappear & 1 \\
\hline 2 & $6 \mathrm{Y}$ & $\mathrm{F}$ & UTI & Simple renal cyst & Increase in size & 1 \\
\hline 3 & $5 \mathrm{Y}$ & M & Abdominal pain & Cyst with septation & Stable & 2 \\
\hline 4 & $10 \mathrm{Y}$ & $\mathrm{F}$ & UTI & Simple renal cyst & Stable & 1 \\
\hline 5 & $2 \mathrm{D}$ & M & Antenatal hydronephrosis & Simple renal cyst & Disappear & 1 \\
\hline 6 & $10 \mathrm{Y}$ & $\mathrm{F}$ & UTI & Simple renal cyst & Stable & 1 \\
\hline 7 & $2 \mathrm{M}$ & M & Fever & Simple renal cyst & Disappear & 1 \\
\hline 8 & $1 \mathrm{M}$ & M & $\begin{array}{l}\text { Dysmorphic features to } \\
\mathrm{R} / \mathrm{O} \text { any abnormality }\end{array}$ & Simple renal cyst & Stable & 1 \\
\hline 9 & $8 \mathrm{Y}$ & $\mathrm{F}$ & UTI & Simple renal cyst & Stable & 1 \\
\hline 10 & $1 \mathrm{M}$ & M & $\begin{array}{l}\text { Cleft palate to } \mathrm{R} / \mathrm{O} \\
\text { any abnormality }\end{array}$ & Simple renal cyst & Stable & 1 \\
\hline 11 & $7 \mathrm{Y}$ & $\mathrm{F}$ & Scoliosis & Simple renal cyst & Stable & 1 \\
\hline 12 & $10 \mathrm{Y}$ & $\mathrm{F}$ & UTI & Simple renal cyst & Stable & 1 \\
\hline 13 & $10 y$ & $\mathrm{~F}$ & Abdominal pain & Simple renal cyst & Stable & 1 \\
\hline 14 & $10 \mathrm{Y}$ & M & Vomiting & Simple renal cyst & Regress in size & 1 \\
\hline 15 & $9 \mathrm{Y}$ & M & Abdominal distention & Simple renal cyst & Surgical resection & 1 \\
\hline 16 & $8 \mathrm{Y}$ & $\mathrm{F}$ & Trauma & Hemorrhagic cyst & Stable & 2 \\
\hline
\end{tabular}

with urinary tract infection (UTI), 2 (12.5\%) with antenatal dilated renal cyst and other clinical presentation not related to urinary system. Simple renal cysts were identified in fourteen patients (Bosniak class I), while hemorrhagic cyst was identified in one patients (Bosniak class II) and simple cyst with thin septation was identified in one patient (Bosniak class II).

Additional magnetic resonance imaging (MRI) was performed for 1 patient with cyst with thin septation (Bosniak class II) shown in Figure 1, as well for the patient with hemorrhagic cyst (Bosniak class II). Computed tomography (CT) was performed for 1 patient with large simple cyst (Bosniak class I) to exclude malignancy shown in Figure 2. There are 15 out of 16 cases followed up by ultrasound for 6 to 12 months interval up to three years. Surgical resection was performed in 1 patient with simple cyst (Bosniak class I) because of significant mass effect on the kidney while the pathological diagnosis came as simple renal cyst. The majority of the patients with Bosniak class I cyst remain stable (62.5\%).

\section{Discussion}

Simple renal cysts are not common in children, their prevalence ranged from $0.22 \%$ to $2 \%$ [3] [8]. Some previous studies have shown that modified Bosniak 

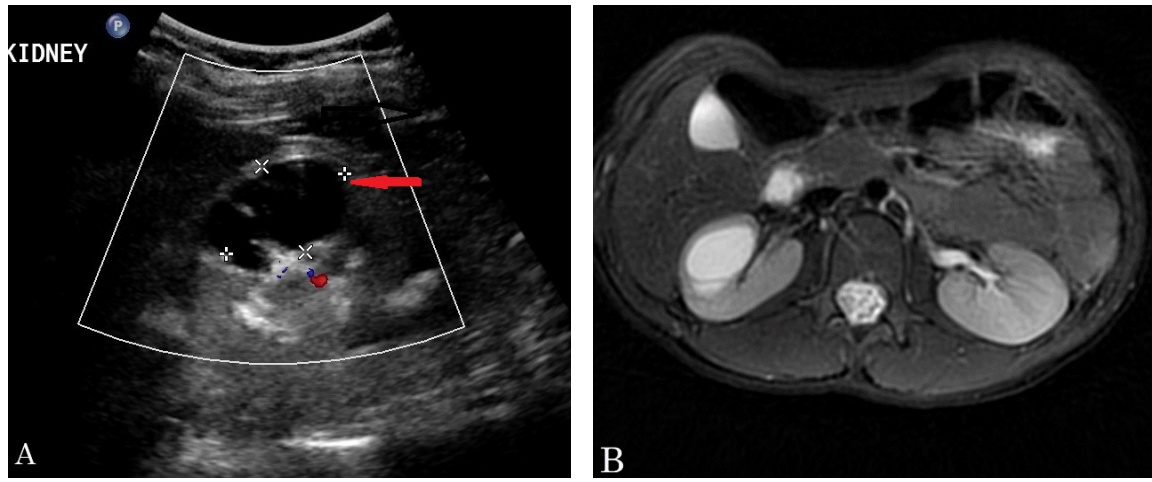

Figure 1. Axial color Doppler (A) US show simple cyst with thin septation (arrow), no internal vascularity or calcification seen. (Bosniak class II). Axial T2WI (B) shows a cyst arising from the mid pole of the right kidney with thin septation.
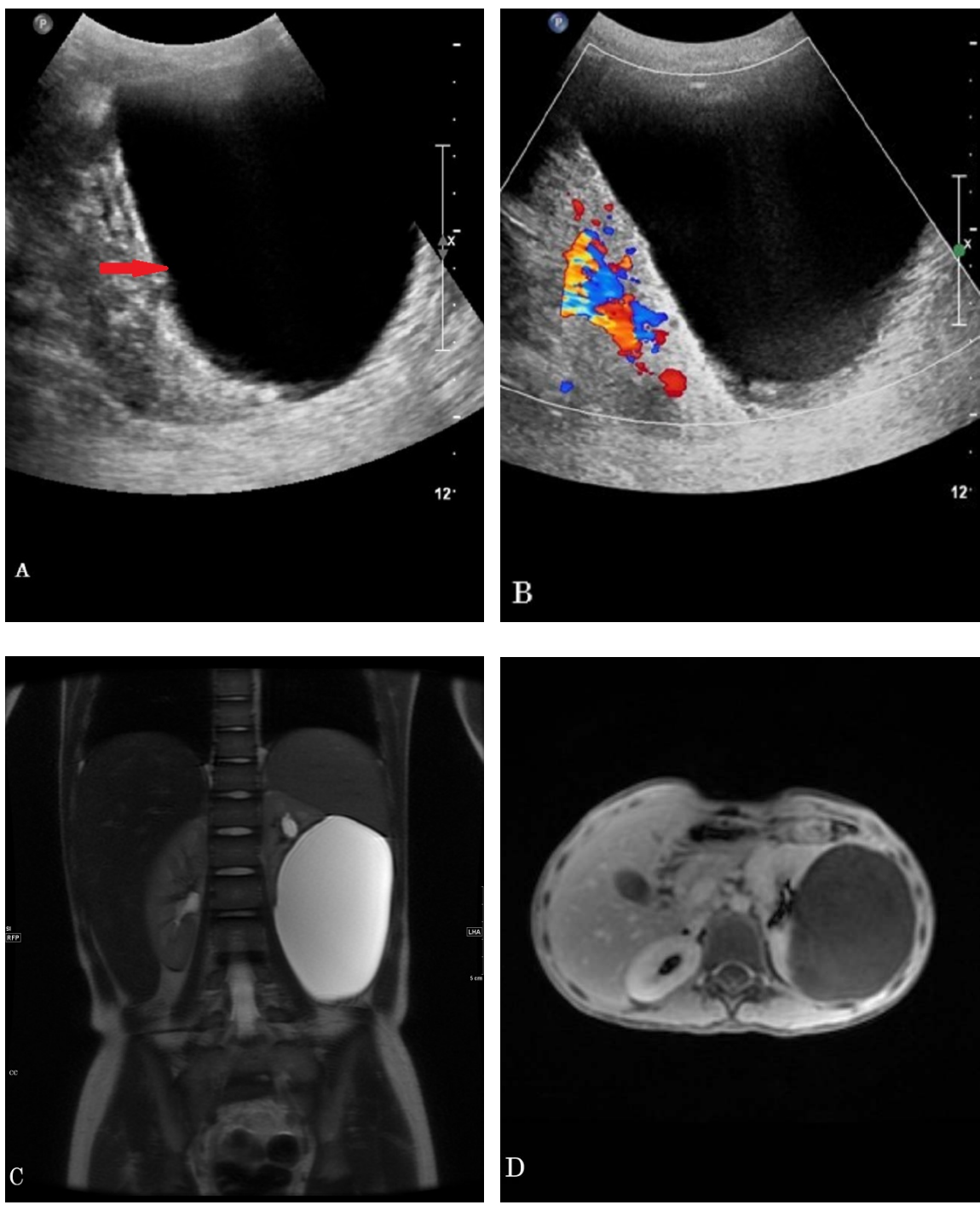

Figure 2. Longitudinal gray scale (A) and color Doppler (B) show simple cyst (arrow) with no septation or internal vascularity (Bosniak class I). Coronal T2WI (C) and Axial T1WI post Gad (D) show large cyst arising from the lower pole of the left kidney with significant mass effect on the kidney. No contrast enhancement detected. 
classification system could provide a defined criteria for both simple and complex cysts in children which may help physicians in the management of the renal cyst [1] [4] [9].

Modified Bosniak classification based on US findings categories' renal cysts in four grades where Simple cysts are classified as (Grade I, II) while complex cyst as (Grade III, IV) (Table 1). This classification system guides renal cyst management in adult patient and has been used widely [3] [10]. However, in pediatric patients management of renal cyst mainly depends on clinical presentation and physician preference with no agreed guidelines [11].

Simple renal cyst is round, thin-walled, anechoic, nonseptated, separate from the collecting system, and has no Doppler blood flow. Differential diagnosis includes the first manifestation of other cystic diseases, caliceal diverticulum, cystic dysplasia, hydatid cysts or posttraumatic kidney cysts [12]. while more complex renal cyst with soft tissue component, thick septation and Doppler flow has more diagnostic dilemma as it raise the suspension of benign multilocular cystic nephroma and cystic nephroblastoma "Wilms tumor" which is very rare [13].

Our study was conducted to establish the efficacy of modified Bosniak classification in pediatric population.

We noticed that asymptomatic simple renal cyst diagnosed on the bases of Modified Bosniak classification, which are majority of our cohort can safely be managed by follow up by renal US. On the contrary, symptomatic renal cyst need further work up like MRI and CT and could require surgical resection like one case in our study.

Saltzman A et al. [4] reported 22 pediatric patients with renal cysts detected in renal US. they conclude that cystic renal lesions in children with a modified Bosniak class of 1 or 2 were most often benign, while class 3 or 4 lesions warranted surgical excision. Another study by Karmazyn B [1] which includes both simple and complex renal cysts in children concluded that no children with grade I or II showed any malignant cell in the surgical resection and US based follow is sufficient for such group.

Our study showed most simple renal cysts stayed unchanged in the follow up study, which is similar to multiple previous studies [14] [15] [16]. Only one case in our serious needed surgical resection because of the significant mass effect on the ipsilateral kidney. One case with hemorrhagic cyst showed interval regression in our serious.

Our study limitation include: small sample size and retrospective nature are major limitations of our study but our finding are consistent with previous studies.

\section{Conclusion}

Our study highlighted that the Modified Bosniak classification can safely be used in the monitoring and management of incidentally detected simple renal cysts (Bosniak I \& II) in the pediatric patients. There are a very few studies on this 
subject. Further studies with larger sample size should be conducted to validate the Modified Bosniak Classification use in pediatric renal cyst diagnosis and management. Follow up for Bosniak type I and II is every 6 months for 3 years or until the cyst disappears by ultrasound.

\section{Statement of Ethics}

The research was approved by King Abdullah international Medical research center, Riyadh, KSA.

\section{Author Contributions}

Amna Kashgari: write the main article, review the images, and collect the references. Eman Ajlan: collect the data, write the results and the table. Abdullah Al Hammad: review the images. Syed Jamil: review and correct the article grammar.

\section{Conflicts of Interest}

The authors declare no conflicts of interest regarding the publication of this paper.

\section{References}

[1] Karmazyn, B., Tawadros, A., Delaney, L.R., Marine, M.B., Cain, M.P., Rink, R.C., et al. (2015) Ultrasound Classification of Solitary Renal Cysts in Children. Journal of Pediatric Urology, 11, 149.e1-149.e6. https://doi.org/10.1016/j.jpurol.2015.03.001

[2] McHugh, K., Stringer, D.A., Hebert, D. and Babiak, C.A. (1991) Simple Renal Cysts in Children: Diagnosis and Follow Up with US. Radiology, 78, 383e5. https://doi.org/10.1148/radiology.178.2.1987597

[3] Henske, E.P., Thorner, P., Patterson, K., Zhuang, Z. and Bernstein, J. (1999) Renal Cell Carcinoma in Children with Diffuse Cystic Hyperplasia of the Kidneys. Pediatric and Developmental Pathology, 2, 270-274. https://doi.org/10.1007/s100249900123

[4] Saltzman, A., Carrasco, A., et al. (2018) Can a Modified Bosniak Classification System Risk Stratify Pediatric Cystic Renal Masses? Journal of Urology, 200, 434-439. https://doi.org/10.1016/j.juro.2018.03.076

[5] Terada, N., Ichioka, K., Matsuta, Y., Okubo, K., Yoshimura, K. and Arai, Y. (2002) The Natural History of Simple Renal Cysts. Journal of Urology, 167, 21-24. https://doi.org/10.1016/S0022-5347(05)65373-6

[6] Adachi, T., Nakatani, T., Minami, H., Ikemoto, S., Esaki, K., Morimoto, H., et al. (2003) Renal Cell Carcinoma with Hemorrhagic Cyst Formation in a 4-Year-Old Boy. International Journal of Urology, 10, 267-270. https://doi.org/10.1046/j.1442-2042.2003.00616.x

[7] Kadekawa, K., Miyazato, M., Saito, S., Morozumi, M., Matsuzaki, A., Yoshimi, N., et al. (2009) Renal Cell Carcinoma Originating in a Renal Cyst in a 12-Year-Old Girl. Journal of Pediatric Surgery, 44, e5-e7. https://doi.org/10.1016/j.jpedsurg.2009.08.022

[8] Bayram, M.T., Alaygut, D., Soylu, A., Serdaroğlu, E., Çakmakçı, H. and Kavukçu, S. (2004) Clinical and Radiological Course of Simple Renal Cysts in Children. Urology, 83, 433-437. https://doi.org/10.1016/j.urology.2013.08.055 
[9] Wallis, M.C., Lorenzo, A.J., Farhat, W.A., Bägli, D.J., Khoury, A.E. and Salle, J.L. (2008) Risk Assessment of Incidentally Detected Complex Renal Cysts in Children: Potential Role for a Modification of the Bosniak Classification. The Journal of Urology, 180, 317-321. https://doi.org/10.1016/j.juro.2008.03.063

[10] Park, B.K., Kim, B. and Kim, S.H. (2007) Assessment of Cystic Renal Masses Based on Bosniak Classification: Comparison of CT and Contrast-Enhanced US. European Journal of Radiology, 61, 310-314. https://doi.org/10.1016/j.ejrad.2006.10.004

[11] Warren, K.S. and McFarlane, J. (2005) The Bosniak Classification of Renal Cystic Masses. BJU International, 95, 939-942. https://doi.org/10.1111/j.1464-410X.2005.05442.x

[12] Gimpel, C., Avni, E., Breysem, L., et al. (2019) Imaging of Kidney Cysts and Cystic Kidney Diseases in Children: An International Working Group Consensus Statement. Radiology, 290, 769-782. https://doi.org/10.1148/radiol.2018181243

[13] Bindhu, J., Imtiaz, A., Kumar, R.V. and Thejaswini, M.D.R.T. (2010) Cystic Variant of Favorable-Histology Wilms' Tumor Presenting with Osteolytic Metastasis to the Ribs. Journal of Postgraduate Medicine, 56, 28-30. https://doi.org/10.4103/0022-3859.62436

[14] Park, H. and Kim, C. (2015) Natural 10-Year History of Simple Renal Cysts. Korean Journal of Urology, 56, 351-356. https://doi.org/10.4111/kju.2015.56.5.351

[15] Murthi, G.V., Azmy, A.F. and Wilkinson, A.G. (2001) Management of Simple Renal Cysts in Children. Journal of the Royal College of Surgeons of Edinburgh, 46, $205 \mathrm{e} 7$.

[16] Whelan, T.F. (2010) Guidelines on the Management of Renal Cyst Disease. Canadian Urological Association Journal, 4, 98-99. https://doi.org/10.5489/cuaj.10023 